\title{
FORMULATION OF SITE-SPECIFIC MUCOADHESIVE LIQUID SUPPOSITORIES AS A METHOD TO DECREASE HEPATOTOXICITY IN RABBITS
}

E. M. Ramadan*, Th. M. Borg and M. O. Elkayal

Department of Pharmaceutics, Faculty of Pharmacy, Mansoura University, Mansoura, Egypt

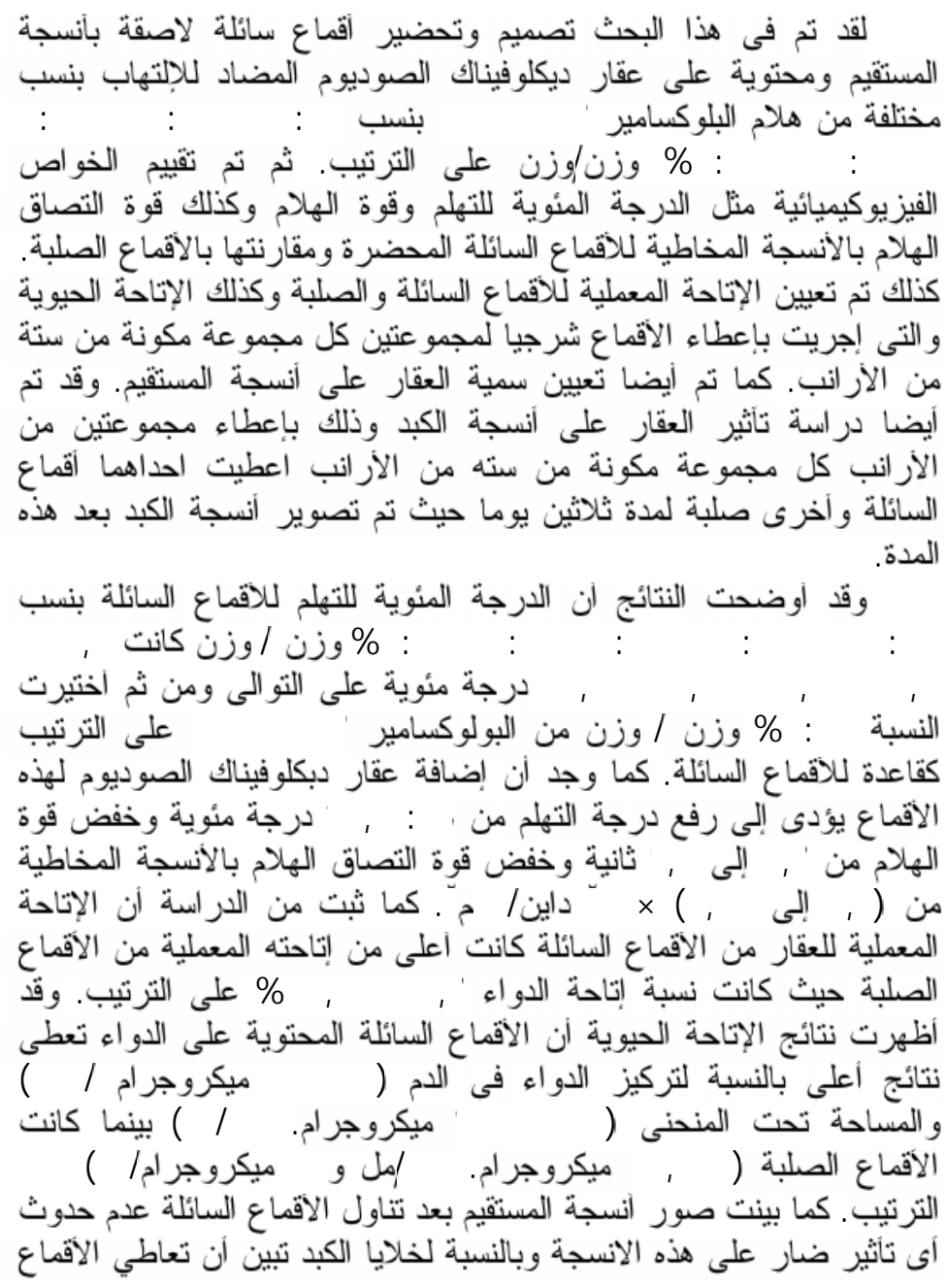

Received in 16/10/2008, Received in revised form in 30/12/2008 \& Accepted in 31/12/2008 


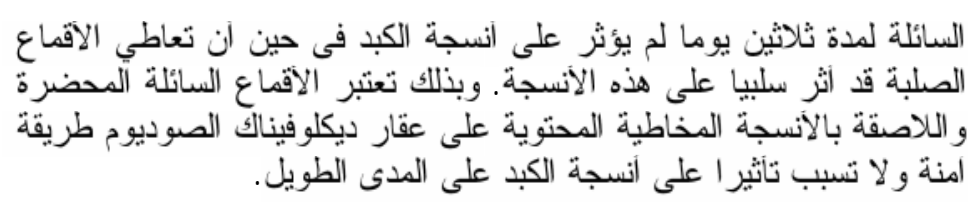

Mucoadhesive liquid suppositories containing diclofenac sodium (DS) as a NSAID were prepared using poloxamers as a liquid suppository base. Various formulations composed of different ratios of P407 and P188 (10/20, 15/15, 21/9, 24/6 and $27 / 3 \% w / w$ of $P 407 / P 188)$ were prepared. The physicochemical characters; the gelation temperature, gel strength and mucoadhesive properties of the prepared suppositories were evaluated and compared with conventional suppositories. The dissolution and pharmacokinetic parameters of DS from such suppositories were also estimated. It was also important to study the histopathological changes in rabbit rectum and liver after administration of liquid and conventional suppositories.

The gelation temperatures were 49.5, 45.5, 32.5, 22.5 and $20.5^{\circ} \mathrm{C}$ for $10 / 20,15 / 15,21 / 9,24 / 6$ and $27 / 3 \% \mathrm{w} / \mathrm{w}$ of $\mathrm{P} 407 / \mathrm{P} 188$, respectively. P407/P188 mixture in the concentration of $21 / 9 \%$, $w / w$ was selected as the system of choice since it exhibited adequate physicochemical properties. The addition of DS increased the gelation temperature (from 18 to $32.5^{\circ} \mathrm{C}$ ) for $21 / 9$ poloxamer mixture and reduced the gel strength (from $4.03 \mathrm{sec}$ to $3.4 \mathrm{sec}$ ) and the mucoadhesive force (from 3.5 to $1.72 \times 102 \mathrm{dyne}^{\mathrm{cm}} \mathrm{cm}^{2}$ ). It was found that the dissolution of DS-loaded poloxamer-based suppositories was significantly higher than that from the conventional suppositories (51.3 versus $26.7 \%$, respectively). Furthermore, the pharmacokinetic study showed that DS-loaded poloxamer-based suppositories gave significantly higher initial plasma concentrations, AUC (70.313 $\mu \mathrm{g} . \mathrm{hr} / \mathrm{ml})$ and $C_{\max }(29.417$ $\mu \mathrm{g} / \mathrm{ml}$ ) of DS than did conventional suppositories $(55.023 \mu \mathrm{g} . \mathrm{hr} / \mathrm{ml}$ and $22 \mu \mathrm{g} / \mathrm{ml}$ ), respectively.

Histopathological study of rectal tissues indicated no pathological damage after $6 \mathrm{~h}$ of rectal administration. The histopathological study of liver tissues revealed that no hepatocellular damage occurred after 30 days of administration of DSloaded poloxamer-based suppository; however hepatotoxicity could not be totally avoided by rectal administration of conventional suppositories. DS-loaded poloxamer-based suppository was an effective rectal dosage form with alleviated adverse effects. 


\section{INTRODUCTION}

Hepatic-toxicity (HP) is a potential complication of most prescribed drug ${ }^{1-3}$, presumably due to the central role of the liver in drug metabolism $^{4}$. In a few cases, the adverse liver reactions are predictable and dose-dependent. However, for most drugs, liver injury is idiosyncratic ${ }^{5}$.

Diclofenac sodium (DS), a widely used NSAID, has been associated with a small but significant incidence of $\mathrm{HP}^{6}$. This is ranged from borderline increases in serum transaminases to acute hepatitis? Therefore, it was suggested that DSassociated HP might be more common than previously recognized ${ }^{8}$. In addition, it undergoes significant first-pass metabolism, so that about $50 \%$ of the drug reaches the systemic circulation in the unchanged form following oral administration?

Conventional suppository which may soften or melt lately in the rectum can not be rapidly absorbed in the mucous membranes ${ }^{10 \& 11}$. Furthermore, such suppository, which may reach the end of the colon, has a loss of drug at colonic level and may also allow the carried drugs to undergo the first-pass effect ${ }^{12 \& 13}$.

It was proved that, it is possible to avoid hepatic first-pass elimination of the drug following rectal administration when the drug is administered as low as possible in the rectum $^{14}$. To solve the problems of conventional suppository, it would be desirable to develop a novel intelligent formula such as poloxamer-based liquid suppository ${ }^{12}$ Liquid suppository exhibits a thermoreversible property; it exists as a liquid at room temperature and turns into a gel instantly at physiological temperature. It is also mucoadhesive to the rectal tissues which prevents its migration to the end of the colon so avoids the first-pass metabolism of the administered drug and reduces its $\mathrm{HP}^{15}$.

In addition, Poloxamer 188 and 407 are known to have a suitable mucoadhesive force ${ }^{13}$, low toxicity ${ }^{16}$, less skin irritation ${ }^{12}$, good drug release characteristics ${ }^{17}$ and compatibility with other chemicals.

In this study, DS-loaded poloxamer-based mucoadhesive liquid suppository was developed. The physical parameters were investigated. In addition, the release and pharmacokinetic study of DS from poloxamer gels were performed and compared to conventional suppositories. Furthermore, the safety of liquid suppository to rectal and liver tissues was carried out.

\section{EXPERIMENTAL}

\section{Materials}

DS was kindly supplied by Medical Union Pharmaceutical Co., Abu-Sultan, Ismailia, Egypt. Witepsols $\mathrm{H}_{15} \quad$ (W $\mathrm{H}_{15}$ ) (Amoun Pharmaceutical Co., El-Obour City, Egypt). Poloxamers (P407 and P188) were purchased from Sigma Aldrich, Germany. Flufenamic acid (FFA) was supplied by EL-Nile CO. for Pharmaceuticals \& Chemical Industries, Cairo, Egypt. Acetonitrile, 
methanol and glacial acetic acid were of super gradient HPLC grade (Sigma-Aldrich Chemie, Germany). EDTA (El-Nasr Pharmaceutical Chemicals Co., Cairo, Egypt). Semipermeable membrane tube (spectra membrane tubing no.1) was from Spectrum Medical Industries Inc. (Los Angeles, CA, USA). All other chemicals were of reagent grade and used without further purification.

\section{Equipment}

UV-Vis. Spectrophotometer (UV1601PC, Schimadzu, Japan). High performance liquid chromatography (HPLC) Perkin Elmer, U.S.A., consisted of series 200 LC pump, series 200 vacuum degasser, 600 series link and series $200 \mathrm{UV} /$ visible detector, Column containing BDS hypersil $\mathrm{C}_{18}$, dimensions ( $\mathrm{LxD}$ ) is $150 \times 4.6 \mathrm{~cm}$ and $5 \mu \mathrm{m}$ particle size, Thermo, England. Vortex, Janke and Kunkel, IKA ${ }^{\circledR} \quad$ Labortechnik, Germany. Sonicator, Soniclean, U.S.A. Light microscope (Euromex, Netherland).

\section{Methodology}

Preparation of DS-loaded poloxamer-based suppository

Mixtures of P407 and P188 in concentrations of 10/20, 15/15, 21/9, $24 / 6$ and $27 / 3 \% \mathrm{w} / \mathrm{w}$ were mixed and heated up to $55^{\circ} \mathrm{C}$. DS $(2.5 \% \mathrm{w} / \mathrm{w})$ was then slowly added to the melted base with continuous agitation. The resulting mixtures were moving to the suppository mould. The mixtures were left at $4^{\circ} \mathrm{C}$ until clear solutions were obtained. $\begin{aligned} & \text { Preparation of DS } \\ & \text { suppositories }\end{aligned}$
One gram containing $2.5 \%$ DS were prepared using $\mathrm{WH}_{15}$ as a suppository base by fusion method ${ }^{18}$.

\section{Evaluation of DS-loaded} poloxamer-based suppository

a) Measurement of gelation temperature and gel strength

Gelation temperature was assessed using the tube tilting method ${ }^{19}$. Two milliliter aliquots of the gel was transferred into test tubes, immersed in a water bath at $4^{\circ} \mathrm{C}$ and sealed with aluminum foil. The temperature of water circulation bath was increased in increments of $1{ }^{\circ} \mathrm{C}$ and left to equilibrate for 5 minutes at each new setting. The samples were then examined for gelation, upon tilting through $90^{\circ}$.

The gel strength was determined according to the method adopted by Yun et al. ${ }^{16}$. The gel strength was determined in seconds.

\section{b) Determination of the muco- adhesive force}

The mucoadhesive force of DSloaded poloxamer-based suppository was determined using a mucoadhesive force-measuring device as used by Choi et al. ${ }^{20}$. A section of tissue was cut from the fundus of rabbit rectum and instantly secured with the mucosal side out onto each glass vial. The vials were stored at $36.5^{\circ} \mathrm{C}$ for 10 minutes. One vial connected to the balance and the other fixed with the poloxamer gel added and the height adjusted so that 
the gel was placed between the mucosal sides of both vials. Water from a burette was allowed to fall in a beaker at a constant rate of 10 $\mathrm{mg} / \mathrm{sec}$. Increasing weight of water added gradually would detach the 2 vials. The rectal tissue pieces were changed for each measurement.

Mucoadhesive force, the detachment stress (dyne/cm²), was determined from the minimal weights of water that detached the 2 vials according to the equation of Ch'ng et $a l{ }^{21}$ which states that:

$$
\mathrm{F}=(\mathrm{Ww} \times \mathrm{g}) / \mathrm{A}
$$

Where; $\mathrm{F}$ is the mucoadhesive force $\left(\right.$ dyne $\left./ \mathrm{cm}^{2}\right), \mathrm{Ww}$ is the weight of water (gm), $\mathrm{g}$ is the acceleration due to gravity $\left(\mathrm{cm} / \mathrm{sec}^{2}\right)$ and $\mathrm{A}$ is the surface area of mucous membrane $\left(\mathrm{cm}^{2}\right)$.

\section{Dissolution test}

Various DS-loaded poloxamerbased suppositories (5 g) or conventional suppository (1 g) were inserted into a semi-permeable membrane tube. Both sides of the tube were tied up with a thread to prevent leakage. The semi-permeable membrane tube was then placed in a dissolution tester. Dissolution test was performed at $36.5^{\circ} \mathrm{C}$ using the paddle method at $100 \mathrm{rpm}$ with 400 $\mathrm{ml}$ phosphate buffer ( $\mathrm{pH}$ 6.8) as a dissolution medium. At predetermined intervals, $5 \mathrm{ml}$ of the medium was sampled and filtered. Then, five $\mathrm{ml}$ of fresh phosphate buffer were added to the dissolution medium to compensate. The filtrate was analyzed by UV/vis variable wavelength detector at $276 \mathrm{~nm}$.

\section{Analysis of drug release data}

The release data of DS from poloxamer-based liquid suppositories were analyzed by the exponential equation presented by Peppas ${ }^{22}$ :

$$
\begin{gathered}
\mathrm{Mt} / \mathrm{M}=\mathrm{k} \mathrm{t}^{\mathrm{n}} \\
\log \mathrm{Mt} / \mathrm{M}=\log \mathrm{k}+\mathrm{n} \log \mathrm{t}
\end{gathered}
$$

Where; Mt/M is the fraction of drug released at time $\mathrm{t}, \mathrm{k}$ is the release constant incorporating structural and geometric characteristics of the drug/polymer system and $\mathrm{n}$ is the release exponent indicative of the release mechanism.

\section{Pharmacokinetic study}

\section{a) In-vivo experiment}

Twelve male albino rabbits weighing $1.5 \pm 0.20 \mathrm{~kg}$ were fasted for $24 \mathrm{~h}$ before the experiments but allowed free access to water. The animals were divided into two groups, each comprised of 6 rabbits. The rabbits in each group were administered poloxamer gel A [DS/P407/P188 (2.5\%/21\%/9\%))] or conventional suppository B $\left[\mathrm{DS} / \mathrm{WH}_{15}(2.5 \% / 97.5 \%)\right]$, respectively.

\section{b) Method of administration and blood collection}

The prepared poloxamer gel was administered in a dose of $1.5 \mathrm{gm}$ $\mathrm{gel} / \mathrm{kg}$ body weight (equivalent to $37.5 \mathrm{mg} / \mathrm{kg} \mathrm{DS}$ ), into the rectum $4 \mathrm{~cm}$ above the anus through a stomach sondle needle fitted to a syringe ${ }^{13 \& 23}$. Alternatively, one gram conventional DS suppository was administered in a dose of $37.5 \mathrm{mg} \mathrm{DS} / \mathrm{kg}$ body weight 
into the rectum $4 \mathrm{~cm}$ above the anus. The entrance of the anus was then blocked with a cyanoacrylate adhesive, since the preparation may leak out from the anus during the pharmacokinetic experiment ${ }^{24}$. Two milliliters of blood were collected from the ear vein at various time intervals $(0.5,1,2,3,4,5$, and $6 \mathrm{~h})$ and centrifuged for $10 \mathrm{~min}$. at $3000 \mathrm{rpm}$.

\section{c) Blood sample analysis}

Plasma $(250 \mu \mathrm{l})$ was mixed with 2 $\mathrm{ml}$ acetonitrile solution containing 50 $\mu l$ of flufenamic acid (the internal standard). It was then centrifuged at $3000 \mathrm{rpm}$ for $10 \mathrm{~min}$., to precipitate serum proteins. The supernatant layer was evaporated under $\mathrm{N}_{2}(\mathrm{~g})$. The residue was reconstituted in $50 \mu \mathrm{l}$ of mobile phase. Then, an appropriate aliquot of $(20 \mu \mathrm{l})$ was injected into the HPLC apparatus. Separation was performed on column $\mathrm{C}_{18}(5 \mu \mathrm{m}$ particle size and $150 \times 4.6 \mathrm{~cm}$ dimensions) at ambient temperature. The mobile phase used was a mixture of methanol, water and acetonitrile (50:35:15\% v/v) adjusted to $\mathrm{pH} 3.3$ with glacial acetic acid, and pumped at a flow rate $2.2 \mathrm{ml} / \mathrm{min}$ with UV detection at $273 \mathrm{~nm}^{25}$.

\section{Safety test of rectal tissues in rabbits}

Eighteen male rabbits weighing $1 \pm 0.5 \mathrm{~kg}$ were divided into three groups; each containing 6 rabbits. Group 1 was used as a control. Group 2 was administered the poloxamer gel [DS/P407/P188 (2.5\%/21\%/9\%)] in a dose of $1.5 \mathrm{gm}$ gel $/ \mathrm{kg}$ body weight (equivalent to $37.5 \mathrm{mg} / \mathrm{kg} \mathrm{DS}$ ), into the rectum $4 \mathrm{~cm}$ above the anus through a stomach sondle needle fitted to a syringe ${ }^{23}$. While, group 3 was administered $1 \mathrm{gm}$ conventional DS suppository in a dose of $37.5 \mathrm{mg}$ DS/kg body weight into the rectum 4 $\mathrm{cm}$ above the anus. At $6 \mathrm{hr}$ after administration, the rectum was isolated, rinsed with saline solution, fixed in $10 \%$ neutral carbonatebuffered formaldehyde, embedded in paraffin using an embedding center and cut into slices. The slices were stained with hematoxylin-eosin ${ }^{26}$ and observed under a light microscope.

\section{Histopathological study of rabbit liver tissues}

Eighteen male rabbits weighing $1 \pm 0.5 \mathrm{~kg}$ were divided into 3 groups, as previously mentioned. After 30 days of daily administration of liquid and conventional suppositories in a dose of $2.5 \%$ DS, the animals were sacrificed and the liver was isolated, rinsed with saline solution containing heparin. Then, staining and observation was carried out.

\section{RESULTS AND DISCUSSION}

Gelation temperatures, the temperature at which liquid suppository phase makes transition to gel, were given in Table (1). The results illustrate that the gelation temperatures of plain Poloxamer mixtures were $39.5,37.5,18.0,14.5$ and 14.0 and for DS containing mixture were $49.5,45.5,32.5,22.5$ and 20.5 for the ratios $(10 / 20)$, (15/15), (21/9), (24/6) and (27/3)\% w/w, respectively. 
Table 1: Gelation temperature of different ratios of poloxamer P407/P188 mixtures without and with $2.5 \%$ DS in liquid suppository forms.

\begin{tabular}{|c|c|c|}
\hline \multirow{2}{*}{$\begin{array}{c}\text { Poloxamer P407/P } \\
188 \text { ratio }(\% \mathrm{w} / \mathrm{w})\end{array}$} & \multicolumn{2}{|c|}{ Gelation temperature* $\left({ }^{\circ} \mathrm{C}\right) \pm$ S.D } \\
\cline { 2 - 3 } & Plain mixture & Medicated mixture \\
\hline $10 / 20$ & $39.5 \pm 0.00$ & $49.5 \pm 0.62$ \\
\hline $15 / 15$ & $37.5 \pm 0.08$ & $45.5 \pm 0.50$ \\
\hline $21 / 9$ & $18.0 \pm 0.33$ & $32.5 \pm 0.82$ \\
\hline $24 / 6$ & $14.5 \pm 0.61$ & $22.5 \pm 0.24$ \\
\hline $27 / 3$ & $14.0 \pm 0.11$ & $20.5 \pm 0.54$ \\
\hline
\end{tabular}

$*$ Each value represents the mean of six reading \pm SD.

It was found that, the gelation temperature of poloxamer gel was decreased upon increasing the concentration of P407. These results were in agreement with the same finding reported by Pisal et al. ${ }^{19}$. In addition, Medicated poloxamer mixture P407/P 188 containing 10/20 and $15 / 15 \% \mathrm{w} / \mathrm{w}$ ratio exhibit the gelation temperatures above the desirable range $\left(49.5\right.$ and $45.5^{\circ} \mathrm{C}$ respectively). The formula composed of P407/P188 in a concentration of $21 / 9$ was selected as the system of choice for the liquid suppository base since it exhibits the optimum gelation temperature in the desirable range.

Upon addition of DS, the gelation temperature of 21/9 poloxamer gel was dramatically increased from 18 to $32.5^{\circ} \mathrm{C}$. This was in agreement with the results obtained by Yong et al. ${ }^{26}$. The temperature-dependant gelation of poloxamer solutions could be explained by configurational changes $^{27}$. Poloxamer molecules exhibit a well-arranged zigzag configuration. With increasing temperature, the zigzag configuration of poloxamer is transformed into a close-packed meander configuration, forming a more close-packed and more viscous gel.

The gel strength of the selected formula was measured in order to find the condition which allows the easy insertion of the suppositories with no leakage from the anus ${ }^{28}$. The results obtained revealed that upon addition of $2.5 \%$ DS to the $21 / 9$ poloxamer gel, the gel strength was reduced from $4.03 \mathrm{sec}$ to $3.4 \mathrm{sec}$ (Table 2).

In addition, DS decreased the mucoadhesive force of poloxamer gel to $1.72 \times 10^{2}$ dyne $/ \mathrm{cm}^{2}$. The obtained data are valid and important in prevention the liquid suppositories reaching the end of the colon and keep the pathway of the drug for the first-pass effect ${ }^{26}$. Moreover, the gel cannot damage the rectal mucous membranes $^{20}$.

Figure (1) illustrates the release of DS from conventional and poloxamer suppository. After $6 \mathrm{~h}$, it was observed that the percentage release 
Table 2: The physicochemical properties of 21/9 Poloxamer mixtures without and with $2.5 \%$ DS.

\begin{tabular}{||l|c|c||}
\hline Physicochemical property & $\begin{array}{c}\text { Plain mixture* } \\
(0 \% \mathrm{DS})\end{array}$ & $\begin{array}{c}\text { Medicated mixture } \\
(2.5 \% \mathrm{DS})\end{array}$ \\
\hline Gelation temperature $\left({ }^{\circ} \mathrm{C}\right)$ & $18.0 \pm 0.33$ & $32.5 \pm 0.82$ \\
\hline Gel strength $(\mathrm{sec})$ & $4.03 \pm 0.12$ & $3.4 \pm 0.47$ \\
\hline $\begin{array}{l}\text { Mucoadhesive force }\left(\mathrm{x} 10^{2}\right. \\
\left.\text { dyne } / \mathrm{cm}^{2}\right)\end{array}$ & $3.5 \pm 0.97$ & $1.72 \pm 0.32$ \\
\hline
\end{tabular}

*Each value represents the mean of six reading \pm SD.

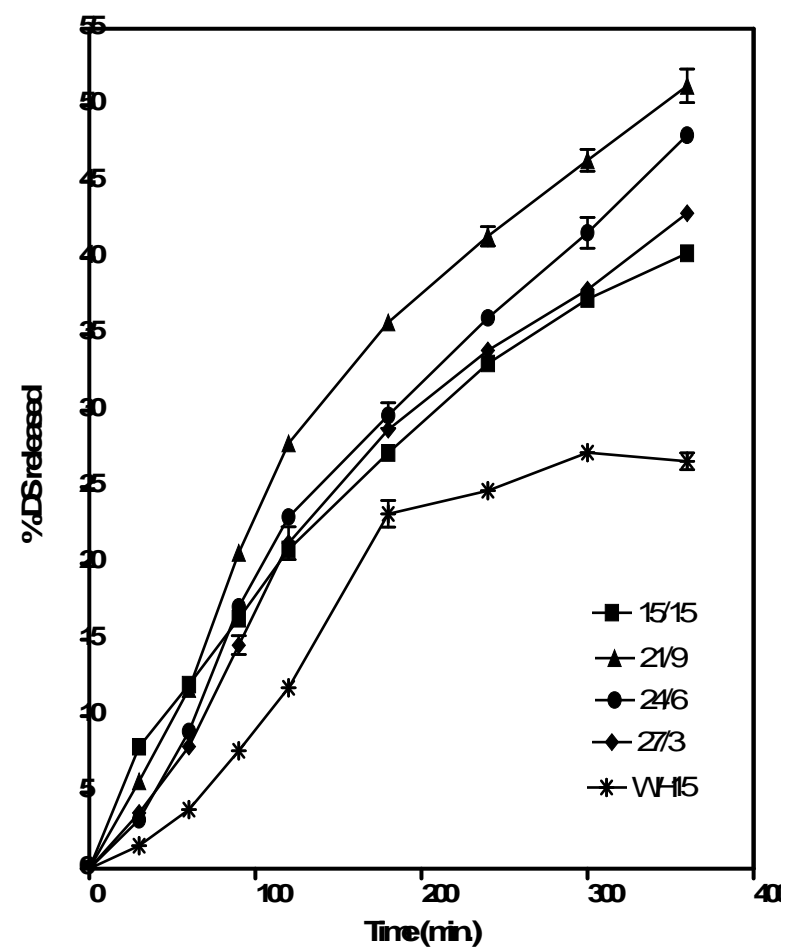

Fig. 1: Release of DS from liquid and conventional suppositories in phosphate buffer $\mathrm{pH} 6.8$. 
of DS from 15/15, 21/9, 24/6 and 27/3\% w/w P407/P188 mixtures were $40.3, \quad 51.3, \quad 48.05$ and $42.9 \%$, respectively, which were generally higher than that from conventional suppository $(26.7 \%)$. As the concentration of P407 increased serially from $21 \%$ to $27 \%$, the percentage release of DS from the liquid suppositories were decreased from $51.3 \%$ to $42.9 \%$ despite decreasing the P188 concentration from $9 \%$ to $3 \%$. The increase in the concentration of higher molecular weight $\mathrm{P} 407$ in the gel increase its viscosity which reduce DS release since the dissolution time is extended and drug diffusion through the gel matrix was prolonged. The decrease of DS release from 27/3 liquid suppository suggests that P407 concentration was the main factor affecting drug release. These results are in agreement with the release data those reported by Tomida et al. ${ }^{29}$.

Data obtained by the plot of $\log$ $\mathrm{M}_{\mathrm{t}} / \mathrm{M}$ versus $\log \mathrm{t}$, kinetic parameters, $\mathrm{n}$ and $\mathrm{k}$, were calculated and listed in Table (3).

As the $\mathrm{k}$ value becomes higher, the drug is released faster. The $\mathrm{n}$ value of 1 corresponds to zero-order release kinetics, $0.5<\mathrm{n}<1$ means non-Fickian (anomalous) release model and $n=0.5$ indicates Fickian diffusion (Higuchi model) ${ }^{22 \& 23}$.

The results illustrate that the slopes of the lines $(n)$ was 1.226 in case of conventional suppositories indicated that the release of DS from $\mathrm{WH}_{15}$ suppository base followed zero-order release mechanism. On the other hand, DS liquid suppositories composed of 15/15, 21/9, 24/6 and $27 / 3 \%$ poloxamer mixture had $n$ values of $0.6746,0.8772,0.947$ and 0.9948 respectively, lying in the range of (0.5-1) suggesting that DS release from liquid suppositories followed non-Fickian or anomalous release that can be attributed to gel erosion in addition to diffusion mechanism ${ }^{22}$.

Figure (2) illustrates the change in mean plasma concentration of DS with time after the rectal administration of liquid or conventional suppositories in rabbits. It was observed that the plasma concentration of DS after $30 \mathrm{~min}$. reached 29.41 and $11.15 \mu \mathrm{g} / \mathrm{ml}$ from poloxamer-based liquid suppository and conventional suppository, respectively. However, starting from $2 \mathrm{hr}$ after suppository administration, the plasma concentrations of DS from liquid suppositories were not statistically different from those from conventional suppositories.

The results that summarized in Table (4) showed that, liquid suppositories gave higher AUC and $\mathrm{C}_{\max }$ of DS than did conventional suppositories $(70.313 \pm 2.43 \mu \mathrm{g} . \mathrm{hr} / \mathrm{ml}$ versus $55.023 \pm 3.852 \mu \mathrm{g} . \mathrm{hr} / \mathrm{ml}$ and $29.417 \pm 1.114 \quad \mu \mathrm{g} / \mathrm{ml} \quad$ versus $22.5 \pm 1.871 \mu \mathrm{g} / \mathrm{ml})$. In addition, liquid suppositories gave faster $\mathrm{T}_{\max }$ of $\mathrm{DS}$ $(0.583 \pm 0.204 \mathrm{hr})$ than did conventional suppositories $(1 \pm 0.03 \mathrm{hr})$.

The increase in the bioavailability of DS from liquid suppositories than conventional suppositories is explained by Yong et $a l^{24}$ who attributed this elevation to the 
Table 3: Release kinetics of DS from liquid and conventional suppositories.

\begin{tabular}{||c|c|c|c||}
\hline Formula & $\begin{array}{c}\text { Release exponent } \\
(\mathrm{n})\end{array}$ & $\begin{array}{c}\text { Kinetic constant } \\
(\mathrm{k})\end{array}$ & $\begin{array}{c}\text { Correlation coefficient } \\
\left(\mathrm{r}^{2}\right)\end{array}$ \\
\hline $15 / 15$ & 0.6746 & 0.797 & 0.9963 \\
\hline $21 / 9$ & 0.8772 & 0.341 & 0.9659 \\
\hline $24 / 6$ & 0.9470 & 0.120 & 0.9555 \\
\hline $27 / 3$ & 0.9948 & 0.145 & 0.9672 \\
\hline $\mathrm{WH}_{15}$ & 1.2260 & 0.0279 & 0.9527 \\
\hline
\end{tabular}

Table 4: Pharmacokinetic parameters of DS delivered by liquid and conventional suppositories.

\begin{tabular}{||c|c|c|}
\hline Parameter $^{*}$ & Liquid suppository & Conventional suppository \\
\left.\hline${\text { AUC }\left(\mu \mathrm{g} . \mathrm{hr}^{-1} \mathrm{ml}^{-1}\right)}\right)$ & $70.31 \pm 2.43$ & $55.02 \pm 3.85$ \\
\hline $\mathrm{T}_{\max }(\mathrm{hrs})$ & $0.58 \pm 0.20$ & $1.00 \pm 0.03$ \\
\hline $\mathrm{C}_{\max }(\mu \mathrm{g} / \mathrm{ml})$ & $29.79 \pm 1.18$ & $23.44 \pm 1.31$ \\
\hline $\mathrm{K} \mathrm{el}^{-1}\left(\mathrm{hrs}^{-1}\right)$ & $0.51 \pm 0.05$ & $0.36 \pm 0.09$ \\
\hline $\mathrm{t}_{1 / 2}(\mathrm{hrs})$ & $1.35 \pm 0.136$ & $2.10 \pm 0.74$ \\
\hline
\end{tabular}

*Each value represents the mean \pm S.D. $(n=6)$.

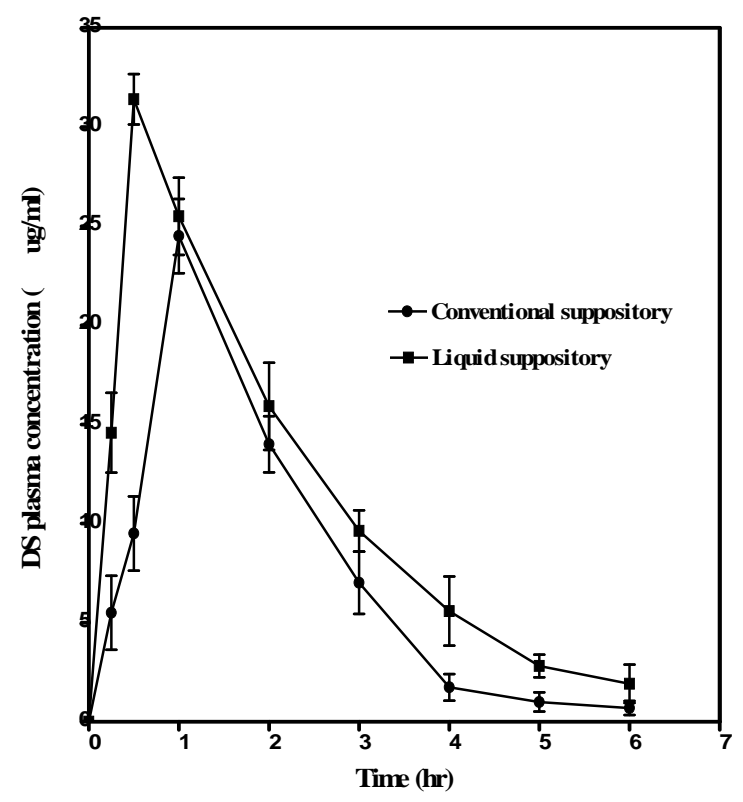

Fig. 2: Plasma concentration-time profiles of DS after rectal administration of lipid and conventional suppositories to rabbits. 
dispensability and the mucoadhesive force of poloxamer gel. This led to the ease of spreading of gel in the rectum, with adequate gelation and the attachment of the gel to the rectal mucous membranes, since the bioadhesive poloxamer gel was a fluid initially ${ }^{13}$.

However, the conventional suppositories are not acting as mucoadhesive and melted gradually to release the drug in the rectal environment. This hypothesis is deeply explained by Realdon et al. ${ }^{30}$ who stated that conventional suppositories gradually melt or soften in the rectal environment before the drug migration through the suppository mass to the rectal environment, which takes longer time. These results were in agreement with the results obtained by Yong et $a l^{24}$. Thus, even if the poloxamerbased liquid suppositories hardly improved the bioavailability of DS compared to conventional suppositories, it would be useful to deliver the drug in a pattern that allows fast absorption in the initial phase. Thus it could be said that, poloxamer-based liquid suppositories is a more effective rectal dosage form for DS.

The safety test of DS liquid and conventional suppository was performed by observed any irritation on the rectal tissues ${ }^{31}$. When comparing the rectal tissues taken from control group 1 with those from group 2, normal rectal mucosa and submucosa were observed. The mucosa showed regular undamaged epithelial cells typical to control, with uniform mucous secretory cells as being illustrated in Figure (3). Generally, no significant changes were found in the normal epithelium where normal mucosa, submucosa and musculosa have been found (B). These findings coincide with those obtained by Choi et al. ${ }^{12}$.

However, the rectal biopsies from group 3 administered DS conventional suppositories showed some significant morphological changes. On comparing to control (A), it was observed that the crypts were seen widely separated from each other indicating edema. The epithelial cells were focally lost in some areas with increased number of inflammatory cells $(\mathrm{C})$.

It can be concluded that the administration of DS in the form of conventional suppositories causes harm to the rectal tissues in the form of rectal inflammation to a great extent which might be accompanied by discomfort and refusal from the patient.

After 30 days of daily administration of DS liquid suppositories, normal liver tissues were observed as shown in Figure 4. The specimens (B) showed normal arrangement of hepatocytes with nuclei relatively uniform in size and staining characteristics. Lymphocytes, eosinophiles and fat vacuoles within the hepatocytes are absent indicating no portal inflammation. Normal periportal hepatocytes and interlobular connective tissue distribution was observed with the absence of hepatocellular swelling. 
A: Control

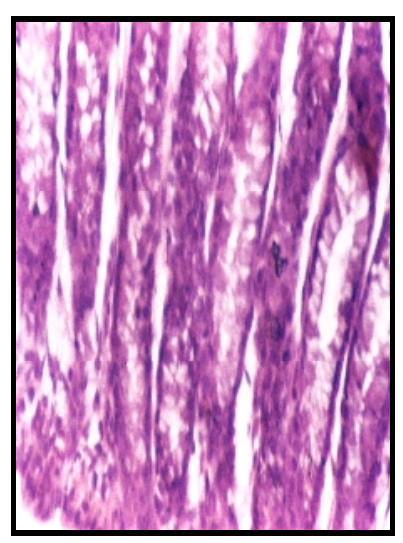

B: Liquid suppositories

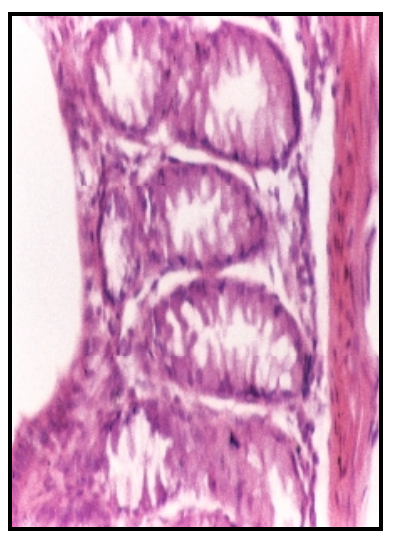

C: Conventional suppositories

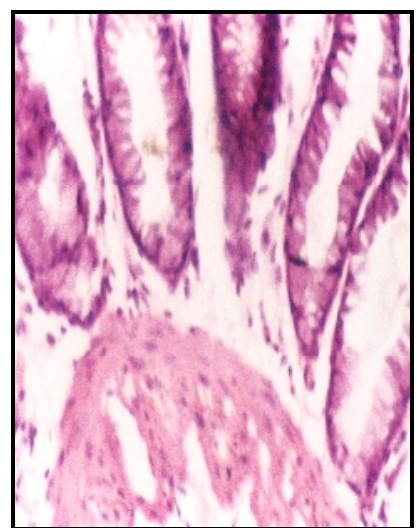

Fig. 3: Morphology of rectal tissue of rabbits after rectal administration of liquid and conventional suppositories: (A) control; (B) liquid suppositories and (C) conventional suppositories.

A: Control

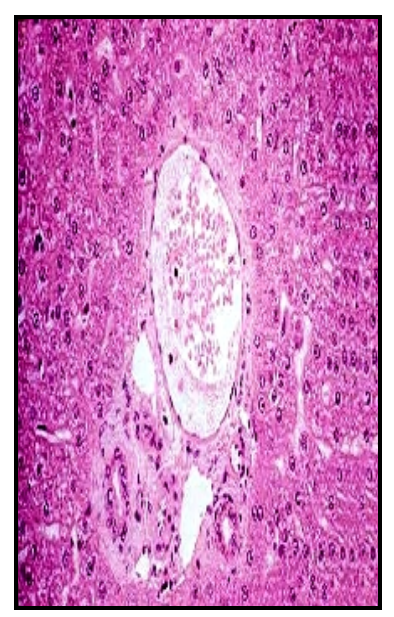

B: Liquid suppositories C: Conventional suppositories

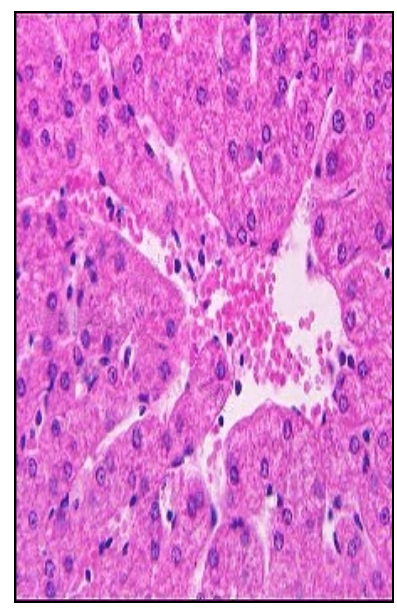

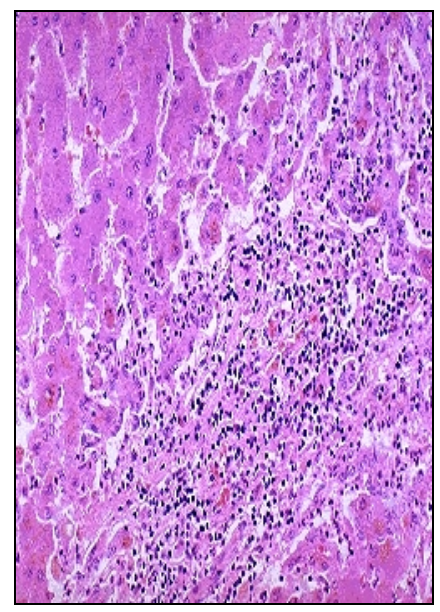

Fig. 4: Morphology of liver tissues of rabbits after administration of DS liquid and conventional suppositories: (A) control; (B) liquid suppositories and (C) conventional suppositories. 
However, after 30 days of daily administration of DS conventional suppositories (C), the hepatocytes showed inflammatory cells indicating marked portal inflammation. Also, large pale-staining cytoplasm indicates the possibility of occurrence of hepatitis. In addition, hepatocellular necrosis in some sites of the tissue was observed. In general, it can be concluded that, DS liquid suppositories caused generally no harm to the liver tissues.

In-situ gelling, mucoadhesive DS liquid suppository composed of DS/P407/P188 (2.5/21/9\%, w/w) exhibit convenient physicochemical properties. It was liquid at room temperature and instantly gelled at physiological temperature. Furthermore, it gave significantly higher initial plasma concentrations of DS indicating that DS could be absorbed faster from poloxamer-based liquid suppositories than from conventional ones. It was safe to the rectal tissues since it caused no irritation or damage to the rectal mucous membrane. In addition, liver tissues were not affected by the prolonged use of DS liquid suppositories.

Thus, DS-loaded poloxamer-based liquid suppository can be used as a safe, mucoadhesive and effective rectal dosage form to avoid the hepatotoxic effect of DS.

\section{REFRENCES}

1- R. L. A. Garcia, A. Ruigomez and H. Jick, Pharmacotherapy, 17, 721 (1997).
2- Urs A. Boelsterli, Toxicology and Applied Pharmacology, 192, 307 (2003).

3- C. S. Yong, J. J. Xuan, S. H. Paek, Y. K. Oh, J. S. Woo, M. H. Lee, J. A. Kim and H. G. Choi, Int. J. Pharm., 321, 56 (2006).

4- R. Weinshilboum, N. Engl. J. Med., 348, 529 (2003).

5- N. Kaplowitz, Clin. Infect. Dis., 38, 44 (2004).

6- C. Benedetta, A. Sallusito and L. H. Felicity, Pharmacotherapy, 29, 1535 (2001).

7- R. Bort, X. Ponsoda, R. Jover, M. J. Gomez-Lechon and J. V. Castell, J. Pharmacol. Exp. Ther., 288, 65 (1999).

8- Y. Masubuchi, S. Nakayama and T. Horie, Hepatology, 35, 544 (2002).

9- Martindale, "The Complete Drug Reference", K. Parfitt, Ed., 32 $2^{\text {nd }}$ Ed., The Pharmaceutical Press, London, UK, 1999, p. 49.

10- A. H. Burstein, K. M. Fisher, M. L. McPherson and C. A. Roby, Pharmacotherapy, 20, 562 (2000).

11- C. J. Eboka, R. S. Okor, J. O. Akerele and S. O. Aigbavboa, J. Clin. Pharm. Ther., 22, 217 (1997).

12- H. G. Choi, J. H. Jung, J. M. Ryu, S. J. Yoon, Y. K. Oh and C. K. Kim, Int. J. Pharm., 165, 33 (1998).

13- C. K. Kim, S. W. Lee, H. G. Choi, M. K. Lee, Z. G. Gao, I. S. Kim and K. M. Park, ibid., 174, 201 (1998). 
14- A. G. De Boer, L. G. J. De Leede and D. D. Breimer, "Controlled Release Rectal Dosage Forms: Site-Specific Administration and Avoidance of Hepatic First-Pass Elimination in Humans and Rats", In "Rectal Therapy", B. Glas and C. J. De Blaey, eds., Pub. Rous. J.R.P., 1983, pp. 6365.

15- H. G. Choi, M. K. Lee, M. H. Kim and C. K. Kim, Int. J. Pharm., 190, 13 (1999).

16- M. O. Yun, H. G. Choi, J. H. Jung and C. K. Kim, ibid., 189, 137 (1999).

17- S. Miyazaki, T. Nakamura, C. Yokouchi and M. Tanaka, Chem. Pharm. Bull., 35, 1243 (1987).

18- M. Asikoglu, G. Ertan and G. Cosar, J. Pharm. Pharmacol., 47, 713 (1995).

19- S. S. Pisal, A. R. Paradkar, K. R. Mahadik and S. S. Kadam, Int. J. Pharm., 270, 37 (2004).

20- H. G. Choi, J. H. Jung, C. S. Yong, J. D. Rhu, J. H. Han, M. K. Lee, K. M. Park and C. K. Kim, J. Control. Rel., 68, 405 (2000).

21- H. S. Ch'ng, H. Park, P. Kelly and J. R. Robinson, J. Pharm. Sci., 74, 399 (1985).

22- N. A. Peppas, Pharm. Acta. Helv., 60, 110 (1985).
23- Y. J. Park, C. S. Yong, H. M. Kim, J. D. Rhee, Y. K. Oh, C. K. Kim and H. G. Choi, Int. J. Pharm., 263, 105 (2003).

24- C. S. Yong, Y. K. Oh, Y. I. Kim, J. C. Kim, B. K. Yoo, J. D. Rhee, K. C. Lee, D. D. Kim, Y. J. Park, C. K. Kim and H. G. Choi, ibid., 301, 54 (2005).

25- Y. El-Sayed, M. Abdel Hamid, M. S. Seliman and N. M. Najib, J. Pharm. Pharmacol., 40, 727 (1988).

26- C. S. Yong, J. S. Choi, Q. Z. Quan, J. D. Rhee, C. K. Kim, S. J. Lim, K. M. Kim, P. S. Oh and H. G. Choi, Int. J. Pharm., 226, 195 (2001)

27- A. Kramaric, A. Resman, B. Kofler and J. Zmittek, European Patent, 0551626 (1992).

28- M. L. Veyries, G. Couarraze, S. Geiger, F. Agnley, L. Massias, B, Kunzli, F. Faurisson and B. Rouveix, Int. J. Pharm., 192, 183 (1999).

29- H. Tomida, M. Shinohara, N. Kuwada and S. Kiryu, Acta Pharm. Suec., 24, 263 (1987).

30- N. Realdon, E. Ragazzi, M. Daltzotto and G. DallaFini, G., Int. J. Pharm., 148, 155 (1997).

31- K. Watanabe, S. Yakou, K. Takayama, Y. Machida and K. Isowa, Bio. Pharm. Bull., 16, 391 (1993). 